\title{
Stage IV Oropharyngeal Squamous Cell Carcinoma AJCC v7
}

National Cancer Institute

\section{Source}

National Cancer Institute. Stage IV Oropharyngeal Squamous Cell Carcinoma A/CC v7. NCl Thesaurus. Code C8220.

Stage IV includes: IVA (T4a, N0, M0); (T4a, N1, M0); (T1, N2, M0); (T2, N2, M0); (T3, N2, M0); (T4a, N2, M0); IVB (T4b, Any N, M0); (Any T, N3, M0); IVC (Any T, Any N, M1). T4a: Tumor with moderately advanced local disease. Tumor invades the larynx, extrinsic muscle of tongue, medial pterygoid, hard palate, or mandible. Mucosal extension to lingual surface of epiglottis from primary tumors of the base of the tongue and vallecula does not constitute invasion of larynx. T1: T umor $2 \mathrm{~cm}$ or less in greatest dimension. T2: Tumor more than $2 \mathrm{~cm}$ but not more than $4 \mathrm{~cm}$ in greatest dimension. T3: Tumor measuring more than 4 centimeters in greatest dimension or extension to lingual surface of epig lottis. T4b: T umor with very advanced local disease. T umor invades lateral pterygoid muscle, pteryg oid plates, lateral nasopharynx, or skull base or encases carotid artery. N0: No regional lymph node metastasis. N1: Metastasis in a single ipsilateral lymph node, $3 \mathrm{~cm}$ or less in greatest dimension. N2: Tumor with metastasis in a single ipsilateral lymph node, more than $3 \mathrm{~cm}$ but not more than $6 \mathrm{~cm}$ in greatest dimension, or in multiple ipsilateral lymph nodes, none more than $6 \mathrm{~cm}$ in greatest dimension, or in bilateral or contralateral lymph nodes, none more than $6 \mathrm{~cm}$ in greatest dimension. N3: Tumor with metastasis in a lymph node more than $6 \mathrm{~cm}$ in greatest dimension. M0: No distant metastasis. M1: Distant metastasis. (AJCC 7th ed.) 